OPEN ACCESS

Edited by:

Ranjith Ramasamy,

University of Miami, United States

Reviewed by:

Himanshu Arora,

University of Miami, United States

Carolina Jorgez,

Baylor College of Medicine,

United States

*Correspondence:

Kuladip Jana

kuladip@jcbose.ac.in;

kuladip_jana@yahoo.com;

kuladip.jana@gmail.com

Specialty section:

This article was submitted to

Reproduction,

a section of the journal

Frontiers in Endocrinology

Received: 04 January 2019

Accepted: 12 April 2019

Published: 30 April 2019

Citation:

Banerjee B, Chakraborty S,

Chakraborty P, Ghosh D and Jana $K$ (2019) Protective Effect of Resveratrol

on Benzo(a)Pyrene Induced

Dysfunctions of Steroidogenesis and

Steroidogenic Acute Regulatory Gene

Expression in Leydig Cells.

Front. Endocrinol. 10:272.

doi: 10.3389/fendo.2019.00272

\section{Protective Effect of Resveratrol on Benzo(a)Pyrene Induced Dysfunctions of Steroidogenesis and Steroidogenic Acute Regulatory Gene Expression in Leydig Cells}

\author{
Bhaswati Banerjee $^{1}$, Supriya Chakraborty ${ }^{1}$, Pratip Chakraborty ${ }^{2}$, Debidas Ghosh $^{3}$ and \\ Kuladip Jana ${ }^{1 *}$ \\ ${ }^{1}$ Division of Molecular Medicine, Bose Institute, Calcutta Improvement Trust Scheme VIIM, Kolkata, India, ${ }^{2}$ Department of \\ Infertility, Institute of Reproductive Medicine, Kolkata, India, ${ }^{3}$ Department of Bio-Medical Laboratory Science and \\ Management, Vidyasagar University Midnapore, Midnapore, India
}

Benzo(a)pyrene $[\mathrm{B}(\mathrm{a}) \mathrm{P}]$ is the toxic environmental Polycyclic Aromatic Hydrocarbon $(\mathrm{PAH})$, that exerts male reproductive dysfunctions. In this study the molecular mechanism of $\mathrm{B}(\mathrm{a}) \mathrm{P}$ induced Leydig cell steroidogenic dysfunctions and its protective mechanism of action with a natural Aryl hydrocarbon receptor (AhR) antagonist and anti-oxidant, Resveratrol (Res) has been investigated. B(a)P exposure induced ROS mediated steroidogenic imbalance via activation of p38MAPK and repression of testosterone level as well as other steroidogenic enzymes like CYPIIA1, 3 $\beta-H S D, 17 \beta-H S D$ expressions. $\mathrm{B}(\mathrm{a}) \mathrm{P}$ exposure decreased StAR protein expression along with increased DAX-1, a transcriptional repressor of StAR gene. Along with that $\mathrm{B}(\mathrm{a}) \mathrm{P}$ decreased the expression of SF-1 that acts as a transcriptional inducer of StAR gene expression. The study has established Resveratrol as a potential agent combating the deleterious effect of $\mathrm{B}(\mathrm{a}) \mathrm{P}$ on Leydig cell steroidogenesis. Resveratrol treatment resulted significant protection against $\mathrm{B}(\mathrm{a}) \mathrm{P}$ by scavenging $\mathrm{ROS}$ and modulating the transcriptional regulation of anti-oxidant enzymes. Furthermore, Resveratrol also prevented stress kinase like p38 MAPK activation and increased StAR protein expression through the reduction of DAX-1 expression. Moreover, the testosterone production was efficiently restored with Resveratrol treatment. ChIP assay also revealed that resveratrol improved SF-1expression which further increased the StAR gene expression. Resveratrol acted efficiently against $\mathrm{B}(\mathrm{a}) \mathrm{P}$, through its anti-oxidative properties as well as inhibits p38MAPK and increased steroidogenesis and StAR expression through the modulation of SF-1 gene expression.

Keywords: B(a)P, leydig cell, ROS, StAR, p38 MAPK, SF1 


\section{INTRODUCTION}

Leydig cells comprise the major endocrine compartment of testis and produce testosterone, the major male reproductive hormone, by the process of steroidogenesis. Several investigations have proposed that environmental toxicants induce adverse effects on male reproductive health $(1,2)$. These environmental toxicants possess endocrine disrupting properties. Thus, they interfere with the process of steroidogenesis and prevent testosterone production (3). $\mathrm{B}(\mathrm{a}) \mathrm{P}$ is an environmental $\mathrm{PAH}$ that act as an endocrine disruptor (4). $\mathrm{B}(\mathrm{a}) \mathrm{P}$ is generated in the ambient air from the incomplete combustion of organic fuel. $\mathrm{B}(\mathrm{a}) \mathrm{P}$ induce several health hazards and counted as Group I carcinogen. Our previous findings revealed that $\mathrm{B}(\mathrm{a}) \mathrm{P}$ exposure resulted deleterious effects on male reproductive system and imparted steroidogenic dysfunctions $(5,6)$ at low to moderate exposure. $\mathrm{B}(\mathrm{a}) \mathrm{P}$ induced biological effects are mediated through the Aryl hydrocarbon Receptor (AhR). Ligand bound AhR acts as a ligand-activated transcription factor and induces the transcription of cytochrome enzymes associated with phase I xenobiotic and drug metabolism (like CYP1A1). But the mode of action of $\mathrm{B}(\mathrm{a}) \mathrm{P}$ in Leydig cells is not properly elucidated.

The major function of testicular Leydig cells is to produce the male hormone testosterone, under the influence of Luteinizing hormone (LH). The first and rate-limiting step in steroidogenesis is the transfer of cholesterol across the inner membrane space from the outer mitochondrial membrane to the inner mitochondrial membrane, a process dependent on the action of Steroidogenic Acute Regulatory (StAR) protein (7). The next step involves the oxidative cleavage of the side chain of the substrate cholesterol by CYP11A1, a mitochondrial cytochrome P450 oxidase and its conversion to pregnenolone. In the next step, pregnenolone is further oxidized by the CYP17 group of enzymes in the endoplasmic reticulum to yield a variety of C-19 steroids. In addition; the 3-hydroxyl group is oxidized by $3 \beta$ HSD to produce androstenedione. In the final step, the androstenedione is reduced by $17 \beta$ HSD to yield testosterone $(7,8)$.

In the initial stage of steroidogenesis, cholesterol needs to be transferred from the outer membrane to the inner membrane of mitochondria since the CYP11A1 enzyme is located on the inner mitochondrial membrane. The aqueous space between the outer and inner mitochondrial membrane acts as a barrier to cholesterol transfer because of its hydrophobic nature. As a result, diffusion of cholesterol through this water barrier is very slow and is not able to supply sufficient substrate for adequate testosterone production. Therefore, the mitochondrial cholesterol transfer via StAR becomes the vital step of testosterone biosynthesis (9). Reports suggest that StAR can be regulated by endogenous and exogenous agents, including environmental toxins (10). It is well-demonstrated that environmental PAHs greatly affect LH stimulated Leydig cell testosterone production $(3,4,11)$. Testosterone biosynthesis is known as steroidogenesis and that in turn greatly affects spermatogenesis. The mechanism of $\mathrm{B}(\mathrm{a}) \mathrm{P}$ induced down regulation of StAR expression is not yet explained. The aim of our study was to investigate the mode of action of $\mathrm{B}(\mathrm{a}) \mathrm{P}$ in the inhibition of StAR protein expression and also the subsequent antagonistic effect of Resveratrol (Res) on it.
StAR expression and steroidogenesis involves transcriptional induction. The promoter for StAR has been sequenced for different mammalian species (rat, mouse, human) (12-14) and they share extensive homology. However, StAR gene promoter lacks a consensus cAMP response element (CRE) and, as such, resembles the promoter of several steroid hydroxylase genes that are regulated by cAMP (15). Transcriptional regulation of the StAR gene, in the absence of a consensus CRE, has been demonstrated to be mediated by multiple DNA elements that provide recognition motifs for sequencespecific transcription factors. These include steroidogenic factor 1 (SF-1), CCAAT/ enhancer binding protein (C/EBP), GATA, sterol regulatory element binding protein (SREBP), SP1, CREB/CRE modulator protein (CREM), the activator protein 1 (AP-1) family (Fos and Jun), DAX-1 (dosagesensitive sex reversal-adrenal hypoplasia congenital critical region on the $\mathrm{X}$-chromosome) etc. $(16,17)$. Therefore, it is well-defined that the proximal region of the StAR promoter is the preferential binding site for several transcription factors and they play crucial roles in controlling StAR gene expression.

It has been confirmed that cAMP modulates StAR through a PKA (protein kinaseA) mediated event. PKA activation can regulate StAR directly and indirectly. Indirectly, PKA can induce transcriptional activation by phosphorylating steroidogenic factor 1 (SF1), a transcription factor commonly known to regulate StAR expression. There are multiple SF-1 sites throughout the mammalian StAR promoter (18). These cellular events trigger activation of two transcription factors i.e., SF1 and DAX 1 those are known to be involved in the regulation of StAR gene expression. SF1 up-regulates the expression of StAR protein and several other steroidogenic enzymes (19), while DAX1, that blocks SF-1 activity thus down regulates StAR expression (20). From the previous reports it can be concluded that the ratio between these two transcription factors determines whether the combined effect will either enhance or inhibit steroidogenesis in different steroidogenic cell types and at different stages of development (20).

Recent findings indicate that p38 MAPK regulates steroidogenesis through transcriptional repression of StAR gene (21). Our previous findings established that $\mathrm{B}(\mathrm{a}) \mathrm{P}$ induced testicular steroidogenic dysfunction is associated with the activation of p38MAPK and production of oxidative stress (6). Henceforth, we have tried to delineate the molecular interplay behind $\mathrm{B}(\mathrm{a}) \mathrm{P}$ induced repression of StAR expression in Leydig cells.

Several phytochemicals are receiving overgrowing importance as therapeutic targets against several health-related disorders. Our previous findings suggest that resveratrol (Res), a plant polyphenolic compound possesses protective properties against $\mathrm{B}(\mathrm{a}) \mathrm{P}$ induced reproductive dysfunctions $(5,6)$. To our knowledge, there is no detailed report of the steroidogenicprotective role of resveratrol against $\mathrm{B}(\mathrm{a}) \mathrm{P}$ induced damage in Leydig cells, available in the literature so far. Therefore, this is the first study demonstrating the protective potential of resveratrol and its mechanism of action in normal Leydig cells after acute $\mathrm{B}(\mathrm{a}) \mathrm{P}$ exposure. 
Herein we have investigated the putative mechanism of action of $\mathrm{B}(\mathrm{a}) \mathrm{P}$ induced Lyedig cell steroidogenic dysfunctions and the protective role of resveratrol. Our study has validated the in-vivo findings in in-vitro system to investigate the molecular interplay induced by $\mathrm{B}(\mathrm{a}) \mathrm{P}$ in Leydig cell steroidogenesis and its possible protection with resveratrol.

\section{MATERIALS AND METHODS}

\section{Materials}

$\mathrm{B}(\mathrm{a}) \mathrm{P}, \quad 3,5,4^{\prime}$-trihydroxy-trans-stilbene (resveratrol), 2, 7-dichlorofluorescein diacetate (DCF-DA), DAPI, NAC (N Acetyl Cysteine) all secondary antibodies (HRP and/or FITC tagged) were purchased from Sigma Chemical Company, St. Louis, USA. Testosterone ELISA kit was purchased from Calbiotech (Spring Valley, CA, USA). MTT cell proliferation assay kit was procured from HIMedia, India. TRIZOL reagent was purchased from Invitrogen (Carlsbad, CA, USA.). Verso cDNA synthesis kit was purchased from Thermo Fisher (Waltham, MA, USA). Powerup SYBR green Master Mix (Applied Biosystems, CA, USA). Antibodies for StAR, 3 $\beta \mathrm{HSD}$, 17 $\beta$ HSD, CYP11A1, SF1, DAX1, AhR and $\beta$ actin were purchased from Santa Cruz Biotechnology (Santa Cruz, CA, USA). AntiCYP1A1, phospho p38 MAPK, and p38 MAPK antibodies were procured from Abcam (Cambridge, MA, USA). All the chemicals and reagents were analytical grade.

\section{Methods}

\section{Animals and Drug Treatment}

Adult male Wistar rats (Rattus norvegicus), 8 weeks of age; 150$200 \mathrm{~g}$ body weight were housed in a climate-controlled $(22 \pm$ $2{ }^{\circ} \mathrm{C}$ ) animal room at a constant $12 / 12$-hr light/dark cycle, with free access to food and water. All procedures were performed in accordance with the protocols approved by the Institutional Animal Ethical Committee (IAEC/BI/30/2015). Four animal groups were maintained. For each group $n=10$ were maintained. Group 1: control animals were gavaged the same volume $(0.2 \mathrm{ml})$ of vehicle (Corn oil) for 60 days, Group 2: animals received resveratrol (Res) at the dose of $50 \mathrm{mg} / \mathrm{kg}$ of body weight daily through oral gavage for 60 days, Group 3: animals received $\mathrm{B}(\mathrm{a}) \mathrm{P}$ at the dose of $5 \mathrm{mg} / \mathrm{kg}$ of body weight daily through oral gavage for 60 days and Group 4: animals were gavaged B(a)P (5 mg/kg) along with resveratrol ( $50 \mathrm{mg} / \mathrm{kg}$ of body weight) for 60 days. We have selected the single dose for both $\mathrm{B}(\mathrm{a}) \mathrm{P}$ and resveratrol from our previous studies, as these have been the most effective doses under our experimental set up. Animals receiving vehicle or 50 $\mathrm{mg} / \mathrm{kg}$ body weight resveratrol alone did not show any adverse side effects. Euthanasia was performed by decapitation under sodium pentobarbital anesthesia, and the efforts were made to minimize the pain and sufferings to the animals. Testes were collected after sacrifice of the animals.

\section{Ethics Statement}

The study was performed under strict accordance with the protocols of the National Institute of Health guidelines for the Care and Use of Laboratory Animals (NIH publication No. 85-23 revised 1985: US Department of Health, Education and
Welfare, Bethesda, Maryland, USA). The experimental outline also met the National Guidelines on the Proper Care and Use of Animals in Laboratory Research (Indian Science Academy, New Delhi, India) and the protocol was approved by the Institutional Animal Ethics Committee (IAEC) of Bose Institute, Kolkata, India (Approval No. IAEC/BI/30/2015). The animal breeding and experimental facility are registered with the Committee for the Purpose of Control and Supervision of Experiments on Animals (CPCSEA), Ministry of Environment and Forest and Climate Change, Government of India.

\section{Leydig Cell Isolation}

Decapsulated testes of rats from different study groups were incubated with dissociation buffer (DMEM/F12 containing $0.1 \%$ BSA and $0.25 \mathrm{mg} / \mathrm{ml}$ collagenase) at $34^{\circ} \mathrm{C}$ in a shaking water bath for $15 \mathrm{~min}$. After dissociation the seminiferous tubules were removed by filtration through $100 \mu \mathrm{m}$ nylon mesh. The filtrate was centrifuged $(250 \times \mathrm{g}$ for $10 \mathrm{~min})$, the pellet was resuspended in buffered Hanks' balanced salt solution, and the suspension was mixed with iso-osmotic Percoll in Hanks' balanced salt solution. After centrifugation $\left(20,000 \times \mathrm{g}\right.$ for $60 \mathrm{~min}$ at $\left.4^{\circ} \mathrm{C}\right)$, fractions were collected and washed with dissociation buffer (11). Leydig cell purity was assessed by cytochemical staining for $3 \beta \mathrm{HSD}$. The cell purity consistently was about $85 \%$.

\section{TM3 Cell Culture}

TM3 normal mouse Leydig cell line was obtained from the National Center for Cell Science (NCCS, India). Cells were maintained and propagated in DMEM with various supplements as suggested by NCCS. The cells were incubated in a humidified incubator at $37^{\circ} \mathrm{C}$ with $5 \% \mathrm{CO}_{2}$ and were exposed to $\mathrm{B}(\mathrm{a}) \mathrm{P}$, resveratrol or other reagents when confluency reached $50 \%$ (11). Doses for in-vitro study of the effect of $\mathrm{B}(\mathrm{a}) \mathrm{P}$ and resveratrol were initially based on previous reports $(11,22)$.

\section{Assay of Testosterone Concentration}

Testosterone concentrations were determined in cultured cell media using Calbiotech ELISA kit according to the manufacturer's instructions. The sensitivity of the assay is $0.075 \mathrm{ng} / \mathrm{ml}$. The intra assay co-efficient of variation is $2.9 \%$ and inter assay coefficient of variation is $3.4 \%$.

\section{MTT Cell Viability Assay}

For viability assays, cells were seeded on 96-well-plates at a density of $0.5 \times 10^{5}$ cells/well. Cell viability was measured by using the MTT cell proliferation assay kit (HIMedia). Absorbance was read at $570 \mathrm{~nm}$ on a microplate reader (MolecularDevices). Cell viability was expressed as a percentage of the control culture.

\section{Immuno-Cytochemistry}

For fluorescence imaging, the cells were fixed with $3.7 \%$ formaldehyde and permeabilized with $0.1 \%$ TritonX-100. Then, cells were incubated with the appropriate primary antibody in $1 \% \mathrm{BSA}$ at $4^{\circ} \mathrm{C}$ for overnight. For secondary antibody reaction, cells were incubated with an appropriate fluorescenceconjugated secondary antibody at room temperature. Cell nuclei were counterstained with DAPI (4'6-diamidino-2-phenylindole). The samples were mounted on clean glass slides using Vecta 
TABLE 1 | Sequences of primers for Reverse transcriptase PCR and qRT PCR.

\begin{tabular}{|c|c|c|}
\hline Primer & Forward $\left(5^{\prime}-3^{\prime}\right)$ & Reverse $\left(5^{\prime}-3^{\prime}\right)$ \\
\hline StAR & TTGGGCATACTCAACAACCA & ATGACACCGCTTTGCTCA \\
\hline $3 \beta-H S D$ & CCGCAAGTATCATGACAGA & CCGCAAGTATCAGACAGA \\
\hline $17 \beta-H S D$ & TTCTGCAAGGCTTACCAGG & ACAAACTCATCGGCGGTCTT \\
\hline CYP11A1 & CGCTCAGTGCTGGTCAAAA & TCTGGTAGACGGCGTCGAT \\
\hline SF1 & TCATCCTCTTCAGCCTGGAT & AGGTACTCCTTGGCCTGCAT \\
\hline AhR & GGGATCGATTTCGAAGACATCAG & AACGCCTGGGAGCCTGGAATCTC \\
\hline$\beta$ actin & GGAGATTACTGCCCTGGCTCCTA & GACTCATCGTACTCCTGCTTGCTG \\
\hline StAR (Mouse) & GGAAGTCCCTCCAAGACTAAAC & AGTCCTAGTGTCTCCTGACTAC \\
\hline 3ß-HSD (Mouse) & CACTGGAAGCTGTGTGAAGA & GGGTCAGCACCTGAATAATGA \\
\hline 17ß-HSD (Mouse) & TGCAACATTACCTCCGTAGTC & CAGCTCCGATCGTGACATATT \\
\hline SF1 (qRTPCR) & CGTCTGTCTCAAGTTCCTCATC & ПTTCCTGGGCGTCCTTAC \\
\hline SOD1 (qRTPCR) & TCTAAGAAACATGGCGGTCC & CAGTTAGCAGGCCAGCAGAT \\
\hline SOD2 (qRTPCR) & CTGAGGAGAGCAGCGGTGGT & CTTGGCCAGCGCCTCGTGGT \\
\hline GPx1 (qRTPCR) & CTCTCCGCGGTGGCACAGT & CCACCACCGGGTCGGACATAC \\
\hline Catalase (qRTPCR) & GGCAGCTATGTGAGAGCC & CTGACGTCCACCCTGACT \\
\hline$\beta$ actin (qRTPCR) & CAGCCTTCCTTCTTGGGTATG & GGCATAGAGGTCTTTACGGATG \\
\hline
\end{tabular}

Shield mounting media (Vector Laboratories, Burlingame, CA) and visualized under the confocal microscope (SP8 Leica, Germany). Images were quantified using this formula to calculate the corrected total cell fluorescence (CTCF). $\mathrm{CTCF}=$ Integrated Density-(Area of selected cell $\mathrm{X}$ Mean fluorescence of background readings).

\section{Intracellular ROS Production in Leydig Cells}

Intracellular ROS production was estimated by using 2, 7dichlorofluorescein diacetate (DCF-DA) as a probe according to the method of Kuo and Tang (23). Briefly, $100 \mu \mathrm{l}$ of cell lysate was incubated with the assay media $(20 \mathrm{mM}$ tris- $\mathrm{HCl}, 130 \mathrm{mM} \mathrm{KCl}$, $5 \mathrm{mM} \mathrm{MgCl}_{2}, 20 \mathrm{~mm} \mathrm{NaH}_{2} \mathrm{PO}_{4}, 30 \mathrm{mM}$ glucose and $5 \mu \mathrm{M}$ DCF$\mathrm{DA})$ at $37^{\circ} \mathrm{C}$ for $15 \mathrm{~min}$. The formation of DCF was measured at the excitation wavelength of $488 \mathrm{~nm}$ and emission wavelength of $510 \mathrm{~nm}$ for $10 \mathrm{~min}$ by using spectro-fluorometer (Hitachi) equipped with a FITC filter.

\section{Western Blotting Analysis}

Cells were lysed in RIPA lysis buffer, supplemented with protease and phosphatase inhibitor cocktail (both from Life Technologies). Proteins from cell lysates $(30 \mu \mathrm{g})$ were resolved on $10 \%$ SDS-PAGE and electro-transferred onto PVDF membrane (Millipore). Membranes were incubated with primary antibodies against StAR, CYPIIA1, $3 \beta$ HSD, $173 \beta$ HSD, SF1, DAX1, AhR, CYP1A1, phospho p38MAPK, p38MAPK, and $\beta$ Actin. Next membranes were incubated with respective secondary antibodies and visualized by ECL detection. $\beta$ Actin was used as the internal loading control.

\section{Reverse Transcriptase PCR and qRT PCR:}

mRNA expression of target genes was estimated using semiquantitative reverse transcriptase PCR method. Briefly, total RNA from cells and/or tissue was extracted with TRIZOL reagent (Invitrogen) and cDNA was synthesized according to the manufacturer's instructions. cDNA was subjected to PCR (30 cycles) in $20 \mu \mathrm{L}$ reaction mixture $[10 \times$ PCR buffer, $2.5 \mathrm{mM}$ dNTP, Taq-polymerase $1 \mathrm{U}$, and forward and reverse primers]. The PCR products were resolved by $1 \%$ agarose gel electrophoresis and visualized using Ethidium bromide. The primer sequences are stated in the Table 1. Quantitative RT-PCR was performed using specific primers (Table 1) and amplified using Powerup SYBR green Master Mix (Applied Biosystems) in Real time PCR (Applied Biosystems). Results are presented as relative mRNA expression levels calculated using the formula $2^{-\Delta \mathrm{CT}}$, where $\Delta \mathrm{CT}=\Delta \mathrm{CT}_{\text {target }}-\Delta \mathrm{CT}_{\text {reference }}$ with $\beta$ Actin as the reference gene.

\section{ChIP Assay}

Chromatin immuno-precipitation assay was performed using ChIP assay kit (Millipore) following manufacturer's instructions. Isolated chromatin was precipitated with SF1 antibody. Input DNA, rabbit IgG-pulled DNA served as controls for all the experiments. Immunoprecipitated DNA was then subjected to 40 cycles of PCR using primer pairs specific for StAR promoter region $5^{\prime}$-TGATGCACCTCAGTTACTGG-3' (forward) and $5^{\prime}$ GCTGTGCATCATCACTTGAG-3'(reverse). $\beta$ Actin was used as a nonspecific control for the ChIP experiments. Two percent agarose gel with Ethidium bromide was used to separate and 
examine PCR products. The results were normalized to the chromatin input of the IP.

\section{Statistical Analysis}

The results were expressed as mean \pm SEM. Oneway ANOVA was followed by Dunnett multiple comparison test, except where otherwise indicated. The level of significance was set at ${ }^{* * *}(P<0.001)$; ${ }^{* *}(P$ $\leq$ 0.01-0.001); ${ }^{*}(P \leq 0.01-0.05)$ in respect with the control. Graph Pad Prim 5.0 was used as the statistical analysis software.

\section{RESULTS}

\section{Resveratrol Prevents B(a)P Induced Testicular Leydig Cell Steroidogenic Dysfunctions via ROS Generation and p38 MAPK Activation}

Our findings suggested that $\mathrm{B}(\mathrm{a}) \mathrm{P}$ exposure significantly alters steroidogenesis in testis (6). Herein we have investigated the role of resveratrol (Res) as a potent agent restoring Leydig cell steroidogenic functions. Testosterone is the major male reproductive hormone. Circulating testosterone and

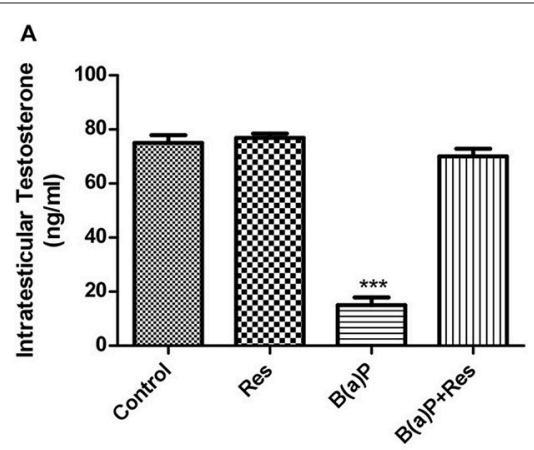

B

C

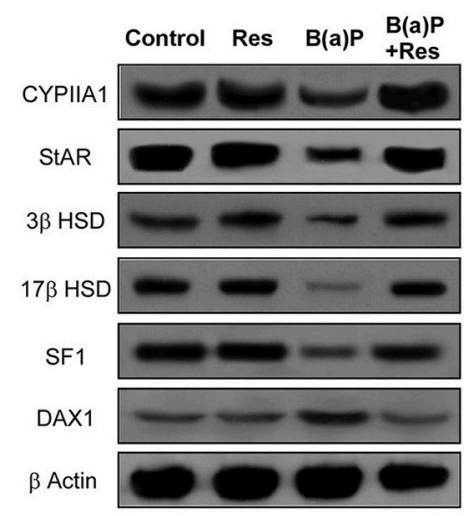

E

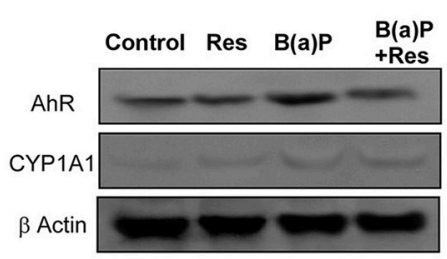

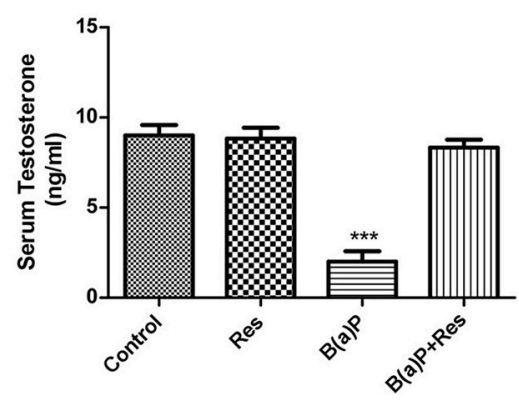

D
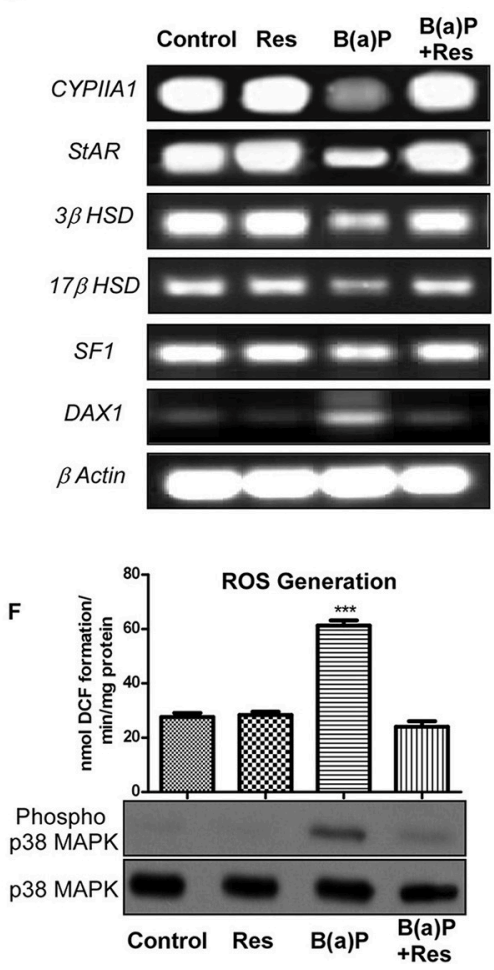

FIGURE 1 | Graphical representation of the level of (A) intra-testicular Testosterone (ng/ml) and (B) serum Testosterone (ng/ml). (C) Western blot and (D) RT-PCR of CYP11A1, StAR, 3 $\beta$ HSD, $17 \beta$ HSD, SF1, and DAX1 with isolated testicular Leydig cells. (E) Western blot of AhR and CYP1A1 with isolated Leydig cells. $\beta$ Actin was used as the loading control. (F) ROS generation in isolated testicular Leydig cells; Western blot of phospho and complete p38 MAPK (lower panel). At least three independent experiments were performed. Histogram is expressing the value of, mean \pm SEM. One-way ANOVA was followed by Dunnett multiple comparison test. The level of significance was set at ${ }^{\star \star \star}(P<0.001)$ as compared with control. B(a)P, Benzo(a)pyrene (5 mg/kg); Res, Resveratrol $(50 \mathrm{mg} / \mathrm{kg})$. 
intra-testicular testosterone levels are the prime indicators for steroidogenic functioning of testis. The findings have shown that $\mathrm{B}(\mathrm{a}) \mathrm{P}$ exposure significantly decreased $(p \leq 0.001)$ testicular and serum testosterone level (Figures 1A,B). Res improved testosterone level in testis and serum (Figures 1A,B). At molecular level CYP11A1, StAR, $3 \beta$ HSD, and $17 \beta$ HSD are strongly involved with the process of steroidogenesis. Their translational and transcriptional regulation must be maintained for sustained testosterone synthesis. For the studies primary Leydig cells were isolated from rat testis upon $\mathrm{B}(\mathrm{a}) \mathrm{P}$ and Res treatment. Western blot and RTPCR with isolated testicular Leydig cells resulted decrease in protein and mRNA expression of major steroidogenic molecules like CYP11A1, StAR, $3 \beta H S D$, and $17 \beta H S D$ (Figures 1C,D). Res improved the steroidogenic profile of testicular Leydig cells, thus the expression of steroidogenic molecules were improved.

SF1 and DAX1 are two transcription factors, involved with the process of steroidogenesis. SF1 promotes steroidogenesis via StAR promoter whereas DAX1 prevents steroidogenesis via blocking SF-1 activity (20). Findings suggested that $\mathrm{B}(\mathrm{a}) \mathrm{P}$ induced decrease in SF1 and increase in DAX1 expression. Res treatment significantly increased SF1 expression and decreased DAX1 expression (Figures 1C,D) in primary Leydig cells.

$\mathrm{B}(\mathrm{a}) \mathrm{P}$ being a $\mathrm{PAH}$, exerts its biological activity via $\mathrm{AhR}$ and metabolized primarily by CYP1A1. The experimental outcomes suggested that Res effectively prevented $\mathrm{B}(\mathrm{a}) \mathrm{P}$ induced increase in AhR expression. Previous findings suggested that primary Leydig cells express very poor level of CYP1A1 (11) as an inbuilt mechanism for protecting cells from toxicant exposure and our findings reconfirmed the fact (Figure 1E).

Oxidative stress results from excessive biosynthesis of Reactive Oxygen Species (ROS), impaired biosynthesis of antioxidants, or a combination of both. ROS is a group of highly reactive oxidizing agents that are involved in several biological processes. But excessive production of ROS damages almost all systems. Balancing ROS and antioxidants is vital for normal testicular functions and sperm fertilization ability (3). Our previous

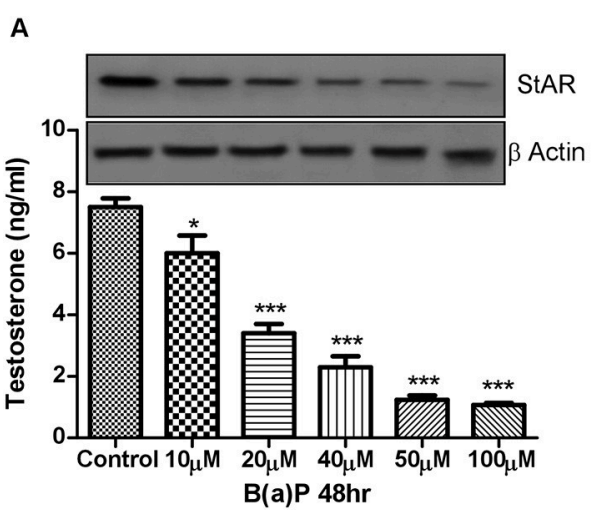

C

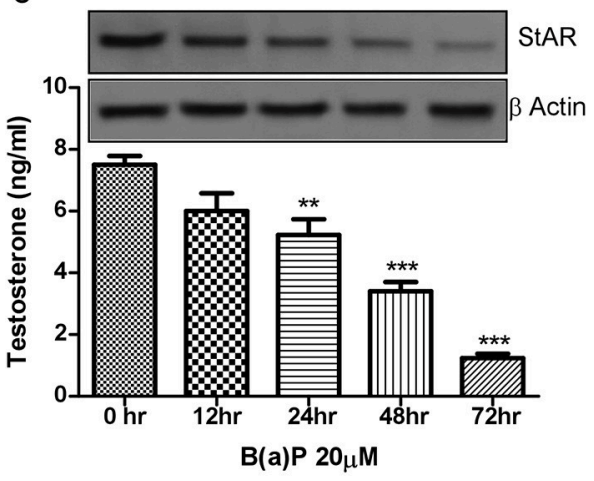

B

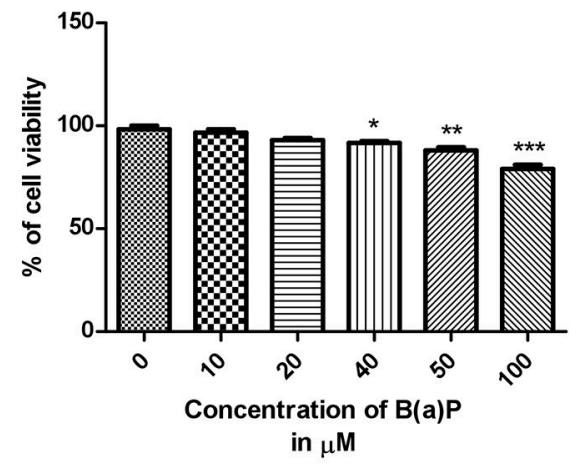

D

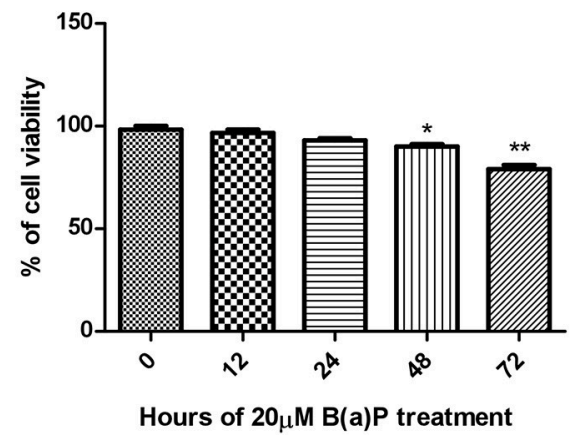

FIGURE 2 | (A) Dose dependent effect of B(a)P (10-100 $\mu \mathrm{M})$ on steroidogenesis in TM3 cells for 48 h. Histogram expressing testosterone level (ng/ml) in media and corresponding western blot of StAR (upper panel). (B) Histogram exhibiting cell viability after treatment with increasing concentrations of $\mathrm{B}(\mathrm{a}) \mathrm{P}(10-100 \mu \mathrm{M})$ in TM3 cells for $48 \mathrm{~h}$. (C) Time dependent effect of B(a)P on steroidogenesis in TM3 cells. Histogram expressing testosterone level (ng/ml) in media and corresponding western blot of StAR (upper panel). (D) Histogram representing cell viability after treatment with increasing concentrations of $\mathrm{B}(\mathrm{a}) \mathrm{P}$ at different time points with $20 \mu \mathrm{M}$ $\mathrm{B}(\mathrm{a}) \mathrm{P}$ in TM3 cells. $\beta$ Actin was used as the loading control. At least three independent experiments were performed. Histograms are expressing the value of, mean \pm SEM. One-way ANOVA was followed by Dunnett multiple comparison test. The level of significance was set at ${ }^{\star \star \star}(P<0.001) ;{ }^{* \star}(P \leq 0.01-0.001) ;{ }^{*}(P \leq$ 0.01-0.05) as compared with control. B(a)P, Benzo(a)pyrene. 
findings suggested that $\mathrm{B}(\mathrm{a}) \mathrm{P}$ induced testicular oxidative stress (6). Res being a potent antioxidant prevented ROS generation in testis. Herein we have investigated the production of ROS in Leydig cells as ROS induces negative impact in Leydig cell steroidogenesis (24). p38MAPK is a significant player behind ROS induced steroidogenic dysfunction (21, 24). Results exhibited that $\mathrm{B}(\mathrm{a}) \mathrm{P}$ induced ROS generation and p38 MAPK activation in isolated primary Leydig cells (Figure 1F). Resveratrol significantly prevented B(a)P induced ROS generation $(p \leq 0.001)$ and also decreased p38 MAPK activation (Figure 1F).

\section{B(a)P Prevents Testosterone Production but Does Not Induce Cell Death in TM3 Leydig Cells}

After obtaining the primary data in isolated Leydig cells, to study the mechanism of action of $\mathrm{B}(\mathrm{a}) \mathrm{P}$ induced steroidogenic dysfunction, we moved toward in-vitro experiments. The principal preliminary finding for our study was to assess the cell viability along with steroidogenesis upon $\mathrm{B}(\mathrm{a}) \mathrm{P}$ exposure. For that purpose dose and time dependent cell viability, testosterone production was checked. StAR being the major important molecule for testosterone production, cellular StAR protein expression at different dose and time point were also checked. Different doses of $\mathrm{B}(\mathrm{a}) \mathrm{P}(10,20,40,50$, and $100 \mu \mathrm{M})$ were studied for 48 hrs. Testosterone level in media was measured and western blots were performed in different groups. From the lower most dose, testosterone synthesis and StAR expression were significantly affected by B(a)P (Figure 2A). Time dependent effect of $\mathrm{B}(\mathrm{a}) \mathrm{P}$ on steroidogenesis in TM3 cells were studied with $20 \mu \mathrm{M}$ dose for $0,12,24,48$, and $72 \mathrm{~h}$. From $24 \mathrm{~h}$ the steroidogenesis was significantly $(p \leq 0.01-0.001)$ affected by $\mathrm{B}(\mathrm{a}) \mathrm{P}$ (Figure 2C).

MTT assay was performed to investigate the effect of $B(a) P$ on TM3 Leydig cell viability. Results indicated that though cell viability was maintained above $50 \%$ at all concentrations of $\mathrm{B}(\mathrm{a}) \mathrm{P}$, but the cell viability was gradually reduced with increasing concentrations of $\mathrm{B}(\mathrm{a}) \mathrm{P}$ (Figure 2B). Extended duration of treatment of $\mathrm{B}(\mathrm{a}) \mathrm{P}$ up to $72 \mathrm{~h}$ resulted significant cell death ( $p \leq 0.01-0.001$ ) numerically (Figure 2D).

Therefore, $20 \mu \mathrm{M}$ B(a)P was chosen as the effective dose for the rest of the study as this particular dose did not induce any significant cell death on the other hand significantly altered the steroidogenic profile of Leydig cell.

\section{Resveratrol Prevents B(a)P Induced Steroidogenic Dysfunction in vitro}

Till now our findings were based upon in-vivo studies. To delineate the mechanism of action of $\mathrm{B}(\mathrm{a}) \mathrm{P}$ in Leydig cell

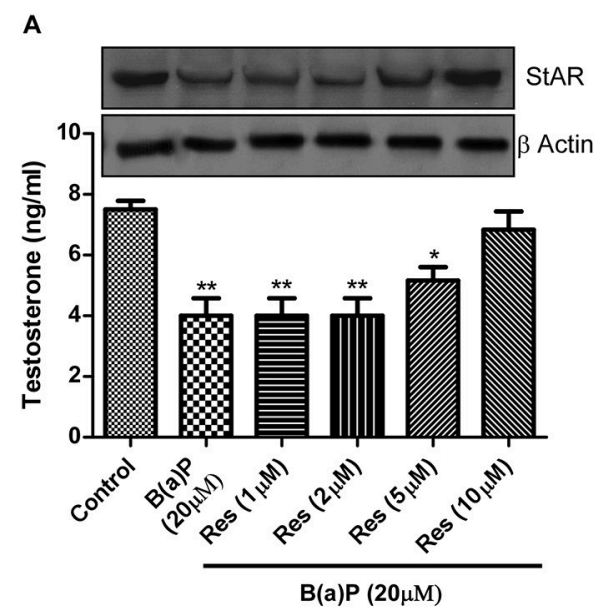

C

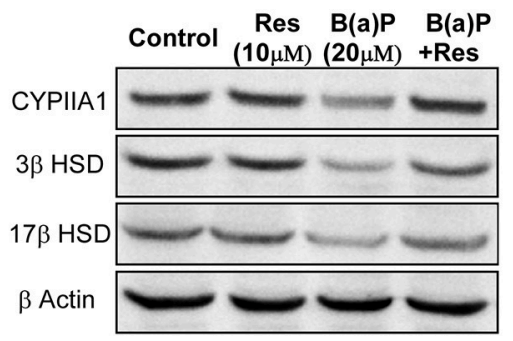

B

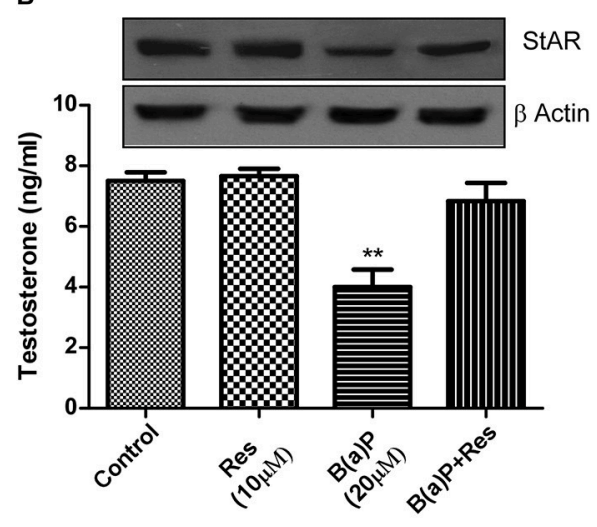

D

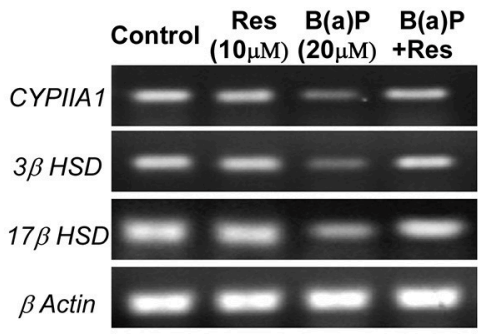

FIGURE 3 | Dose dependent effect of Res on B(a)P induced steroidogenic dysfunction in TM3 cells. (A) Histogram expressing testosterone level in media and corresponding western blot of StAR (upper panel). (B) Histogram expressing testosterone level in media and corresponding western blot of StAR (upper panel) in TM3 cells. (C) Western blot and (D) RT-PCR of CYP11A1, StAR, 3 $\beta$ HSD, and $17 \beta$ HSD in TM3 cells. $\beta$ Actin was used as the loading control. At least three independent experiments were performed. Histograms are expressing the value of, mean \pm SEM. One-way ANOVA was followed by Dunnett multiple comparison test. The level of significance was set at ${ }^{* *}(P \leq 0.01-0.001) ;{ }^{*}(P \leq 0.01-0.05)$ as compared with control. B(a)P, Benzo(a)pyrene; Res, Resveratrol. 
steroidogenic dysfunctions and possible protective action of Res, in-vitro study was the ultimate requisite. We have chosen normal mouse Leydig cell-line TM3 as in-vitro model. In-vitro study with TM3 cell were conducted to delineate the molecular mechanism of $\mathrm{B}(\mathrm{a}) \mathrm{P}$ induced steroidogenic dysfunction and preventive role of Res. Different doses of Res $(1,2,5,10 \mu \mathrm{M})$ were validated against $20 \mu \mathrm{M}$ B(a)P for 48 hrs. Testosterone level in media was measured and western blot for StAR was performed in different groups (Figure 3A). These findings suggested $10 \mu \mathrm{M}$ Res to be effective against $20 \mu \mathrm{M}$ dose of $\mathrm{B}(\mathrm{a}) \mathrm{P}$ (Figures 3A,B).

Next we investigated the expression of steroidogenesis regulatory proteins like CYP11A1, $3 \beta$ HSD and $17 \beta$ HSD in TM3 cells upon $\mathrm{B}(\mathrm{a}) \mathrm{P}$ and Res treatment. Results suggested that Res significantly improved in-vitro steroidogenesis via modulating the protein and mRNA expression of $C Y P 11 A 1,3 \beta H S D$, and $17 \beta$ HSD (Figures 3C,D).

\section{Resveratrol Prevents B(a)P Induced ROS Generation and p38 MAPK Activation and Thus Maintains Leydig Cell \\ Steroidogenesis}

The findings revealed that $\mathrm{B}(\mathrm{a}) \mathrm{P}$ exposure resulted ROS generation in TM3 cells. Further the potential ROS scavenging activity of Res in comparison to well-known anti-oxidant NAC (N Acetyl Cysteine) was checked. Experimental outcomes revealed that Res significantly prevented ROS generation in Leydig cells (Figure 4A). Oxidative stress induces p38 MAPK

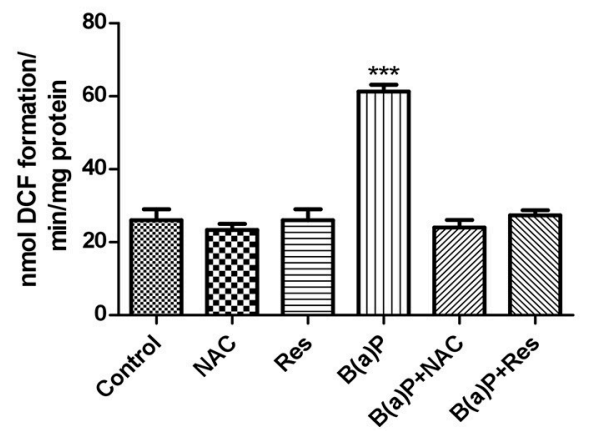

c
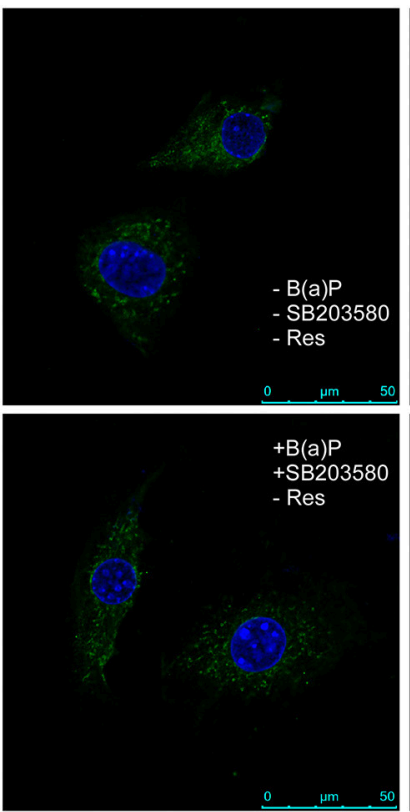

StAR Expression

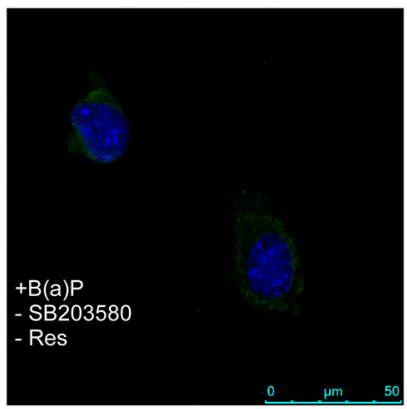

\section{$+\mathrm{B}(\mathrm{a}) \mathrm{P}$}

- SB203580 + Res

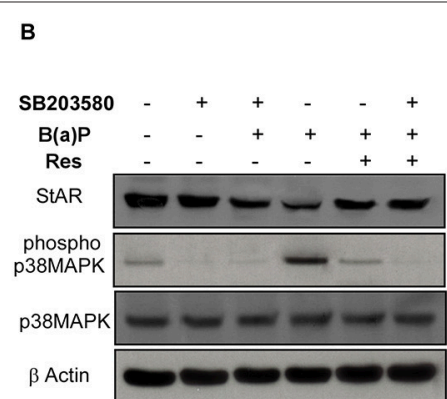

D

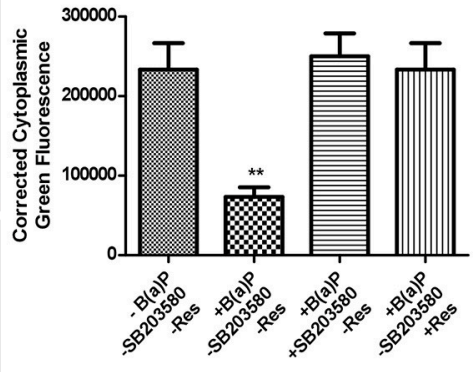

FIGURE 4 | (A) Effect of B(a)P and Res on ROS generation in TM3 cells. Histogram is expressing the value of, mean \pm SEM. One-way ANOVA was followed by Dunnett multiple comparison test. The level of significance was set at ${ }^{\star \star *}(P<0.001) ;{ }^{* *}(P \leq 0.01-0.001)$ as compared with control. (B) Western blot of $S t A R$, phospho and complete p38 MAPK under different experimental conditions. $\beta$ Actin was used as the loading control. (C) Immuno-cytochemistry of StAR expression in different experimental conditions. Nuclei were counter stained with DAPI (blue). Bar $=50 \mu \mathrm{m}$. Magnification $=600 \mathrm{X}$. (D) Corrected fluorescence intensity of StAR protein was quantified and represented as bar diagram (Right panel). Pictures showed representative cells of each population and were representative of three independent experiments. The level of significance was set at ${ }^{\star \star \star}(P<0.001)$; ${ }^{\star \star}(P \leq 0.01-0.001)$ as compared with control. B(a)P, Benzo(a)pyrene; Res, Resveratrol; NAC,N Acetyl Cysteine. 

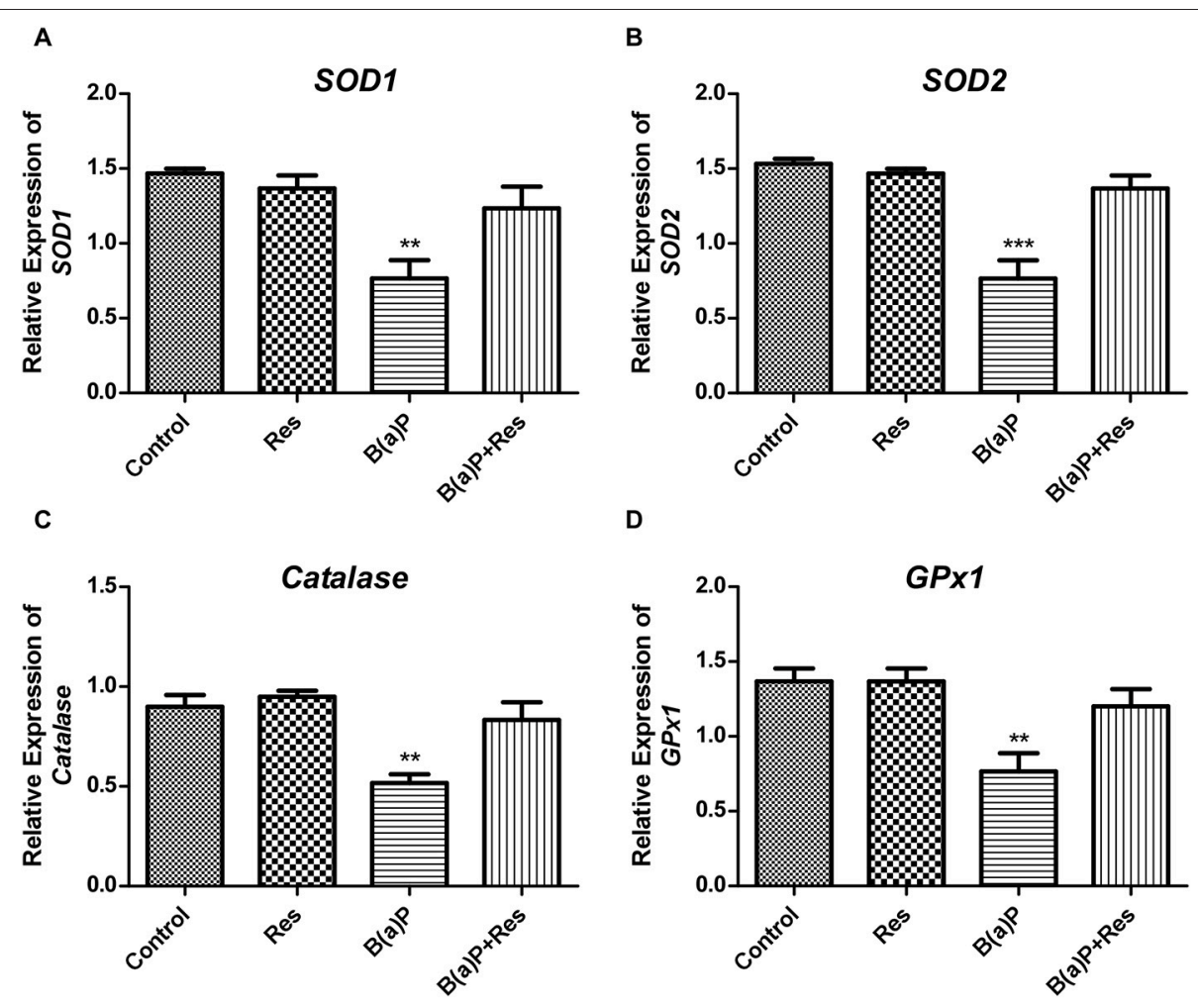

FIGURE 5 | Effect of B(a)P and Res on the changes of the gene expression of anti-oxidant enzymes in isolated Leydig cells. qRT-PCR analyses of (A) SOD1, (B) SOD2, (C) CAT, and (D) GPX1 mRNA levels. Histograms are expressing the value of, mean \pm SEM. One-way ANOVA was followed by Dunnett multiple comparison test. The level of significance was set at ${ }^{\star \star \star}(P<0.001)$; ${ }^{\star \star}(P \leq 0.01-0.001)$ as compared with control. B(a)P, Benzo(a)pyrene; Res, Resveratrol.

activation in different systems $(21,24)$. Oxidative stress induced activation of p38 MAPK has strong correlation with the Inhibition of steroidogenesis via the regulation of StAR (21, 24). We hypothesized that B(a)P induced p38 MAPK activation via ROS generation and activated p38 MAPK inhibited StAR gene expression. To strengthen our hypothesis cells were treated with p38 MAPK blocker SB203580 and ROS with p38 MAPK activation were checked. Western blot analysis revealed that blocking p38 MAPK significantly restored StAR expression (Figure 4B). This finding was reconfirmed by immune-cytochemistry (Figure 4C). Results showed that B(a)P induced decrease in cytoplasmic expression of StAR was retrieved with p38 MAPK blocker SB203580. And Res treatment decreased $\mathrm{B}(\mathrm{a}) \mathrm{P}$ induced activation of p38 MAPK along with restored StAR expression (Figures 4C,D). These findings provided the clear relation between the oxidative stress and steroidogenic dysfunction upon $\mathrm{B}(\mathrm{a}) \mathrm{P}$ exposure.

\section{Resveratrol Up-Regulates B(a)P Induced Alterations in the Gene Expression of Anti-oxidant Enzymes in Leydig Cells}

ROS-induced oxidative stress is the disturbance in the regulation of balance between ROS production and the production of anti-oxidant enzymes. This anti-oxidant defense system is mainly comprised of antioxidant enzymes (e.g., SOD1 [cytosolic CuZn-SOD (superoxide dis-mutase)], SOD2 [mitochondrial Mn-SOD], Catalase [peroxisomal catalase] and GPX1 [cytosolic/mitochondrial glutathione peroxidase 1]. ROS induces reduced functioning of these enzymes. Our previous findings revealed that $\mathrm{B}(\mathrm{a}) \mathrm{P}$ induced decrease in the activity of these enzymes in testis $(5,6)$. Herein we evaluated the mRNA expressions of SOD1, SOD2, Catalase and GPX1in isolated Leydig cells from $\mathrm{B}(\mathrm{a}) \mathrm{P}$ and Res treated animals. Our findings suggested that $\mathrm{B}(\mathrm{a}) \mathrm{P}$ treatment decreased the mRNA expression of SOD1, SOD2, GPX, and Catalase (Figures 5A-D). Whereas, Res treatment significantly up-regulated B(a)P induced alterations in the gene expression of anti-oxidant enzymes (Figure 5).

\section{Resveratrol Modulates Leydig Cell Steroidogenesis via Regulating StAR and SF1}

StAR is a major steroidogenesis regulatory protein in Leydig cells. There are several factors involved with the activity of StAR promoter. Steroidogenic Factor 1 (SF-1/Ad4BP) is a transcription factor whose activity is exerted by binding to the promoter of the StAR gene (25). SF-1 is highly expressed in steroidogenic cell types where it functions to help control the tissue-specific expression of genes involved in the steroid hormone biosynthesis pathway (26). StAR 


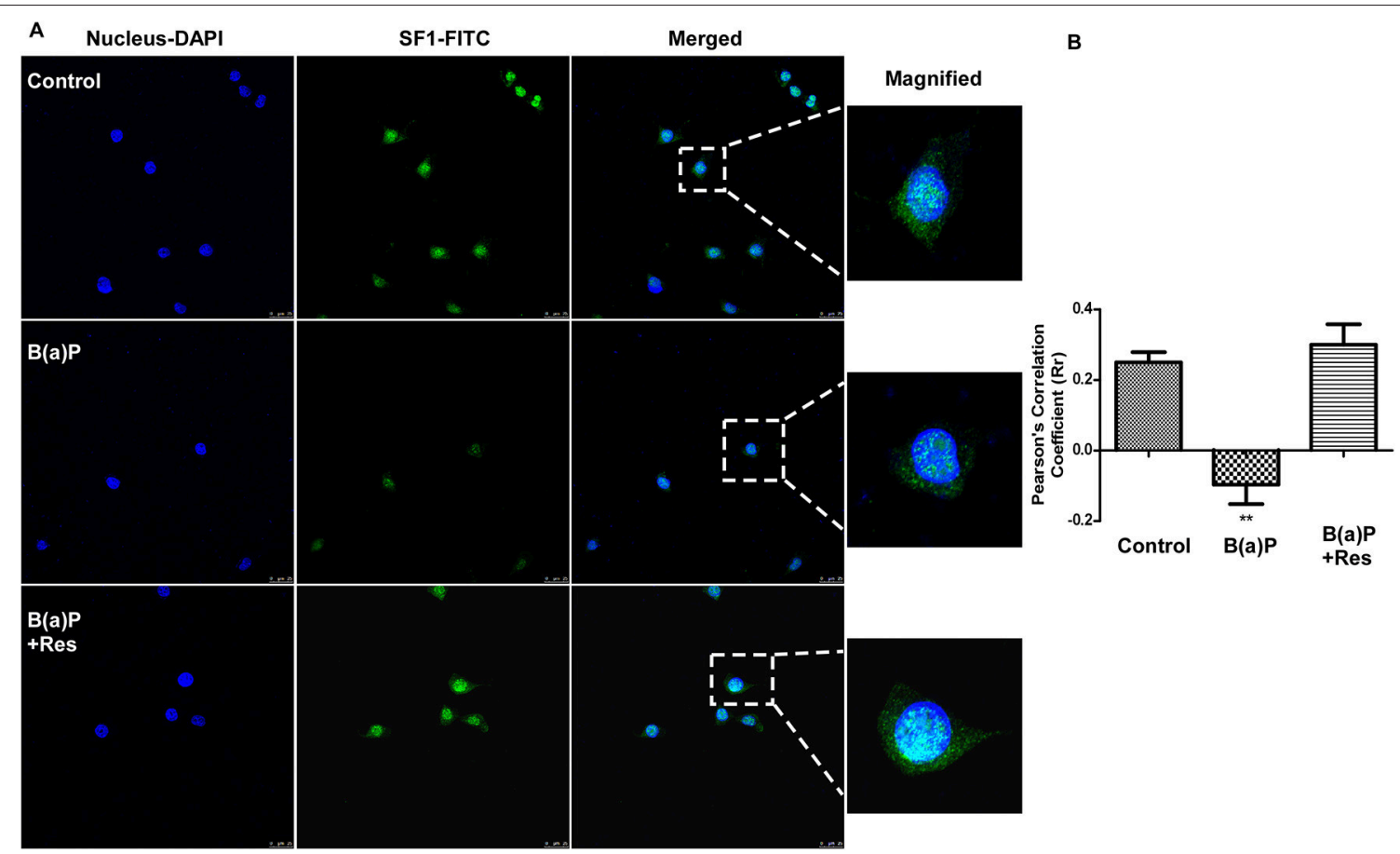

FIGURE 6 | Immuno-cytochemical detection of SF1under the influence of B(a)P and Res in primary Leydig cells. (A) Representative fluorescence images showed the association between SF1 (FITC/green) and nuclei (DAPI/blue). Enlargement of the areas indicated localization of SF1 in nucleus. Pictures showed representative cells of each population and were representative of three independent experiments. Bar $=25 \mu \mathrm{m}$. Magnification 400x. (B) The Pearson's coefficients determining the level of overlap of FITC and DAPI under different experimental groups has been represented graphically. The level of significance was set at ${ }^{\star \star}(P \leq 0.01-0.001)$ as compared with control. B(a)P, Benzo(a)pyrene; Res, Resveratrol.

promoter activity is regulated by the combinative function of different transcription factors. We have found that $\mathrm{B}(\mathrm{a}) \mathrm{P}$ induced decrease in SF1 expression in Leydig cells. Immunocytochemistry in isolated Leydig cells revealed that, being a transcription factor its expression was majorly localized in nucleus. And the nuclear expression of SF1 was improved with Res treatment (Figure 6).

Further findings revealed that $\mathrm{B}(\mathrm{a}) \mathrm{P}$ exposure decreased the mRNA expression of StAR and SF1 in isolated Leydig cells and Res significantly increased the mRNA expression of StAR and SF1 (Figures 7A,B). ChIP assay with the proximal promoter region of StAR with SF1 antibody in Leydig cells exhibited that $\mathrm{B}(\mathrm{a}) \mathrm{P}$ treatment decreased the SF1 recruitment to StAR promoter; whereas Res treatment enhanced the SF1 recruitment (Figure 7C). These findings propose the role of $\mathrm{SF} 1$ as an active target molecule in $\mathrm{B}(\mathrm{a}) \mathrm{P}$ induced steroidogenic dysfunction.

These results altogether concluded that $\mathrm{B}(\mathrm{a}) \mathrm{P}$ induced steroidogenic suppression is a combinatorial effect of oxidative stress, p38MAPK activation, transcriptional down-regulation of StAR via SF1 (Figure 8).

\section{DISCUSSION}

Benzo(a)pyrene $[\mathrm{B}(\mathrm{a}) \mathrm{P}]$ is a common environmental toxicant that is generated from several natural (forest fire, volcanic explosion etc.) and anthropological sources (tobacco smoke, vehicular exhaust, industrial smoke etc.).
With the advancement of human civilization, exposure of environmental $\mathrm{PAH}$ like $\mathrm{B}(\mathrm{a}) \mathrm{P}$ has increased significantly and general population are exposing low to moderate level of $\mathrm{B}(\mathrm{a}) \mathrm{P}$. This leads the male reproductive health under constant threat.

Our previous findings suggested that $\mathrm{B}(\mathrm{a}) \mathrm{P}$ induces apoptosis in testicular spermatogonial germ cell population. But surprisingly $\mathrm{B}(\mathrm{a}) \mathrm{P}$ cannot induce apoptosis in the steroidogenic Leydig cells but, testicular steroidogenesis is hindered. These findings persuade us to unravel the molecular crosstalk behind $\mathrm{B}(\mathrm{a}) \mathrm{P}$ induced disturbance in steroidogenic mechanism. Our previous findings proposed resveratrol (Res) as a potential warrior against $\mathrm{B}(\mathrm{a}) \mathrm{P}$. Herein the mode of action of Res against $\mathrm{B}(\mathrm{a}) \mathrm{P}$ in steroidogenic dysfunction in Leydig cell was investigated.

Leydig cells comprise the steroidogenic compartment of testis. In adult testis these cells possess specialized properties to proliferate rarely and being less susceptible to apoptosis (27).

Our previous findings suggested that $\mathrm{B}(\mathrm{a}) \mathrm{P}$ exposure induce apoptosis particularly to the testicular germ cell population $(5,6)$. This finding is consistent with previous report (11). Our findings reveal that Leydig cells express very poor level of CYP1A1. CYP1A1 is the major molecule that is involved with the metabolic modulation of $\mathrm{B}(\mathrm{a}) \mathrm{P}$ to its toxic form (28). Therefore, we presume that in testis $\mathrm{B}(\mathrm{a}) \mathrm{P}$ execute exclusive molecular signaling in Leydig cells. 
A

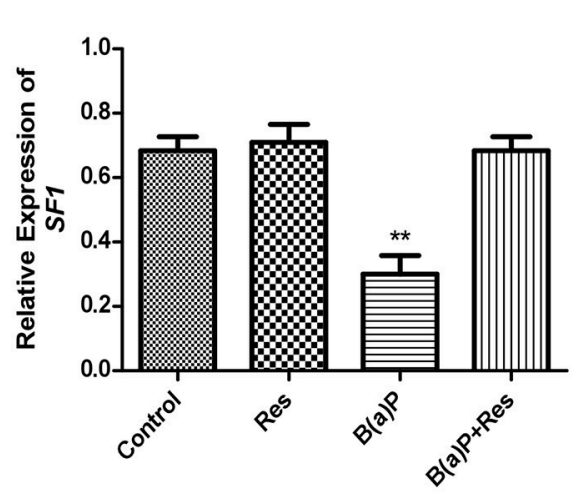

C

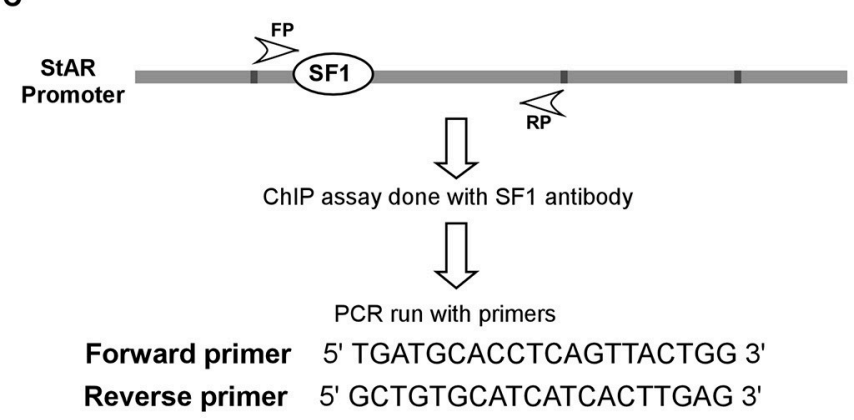

B

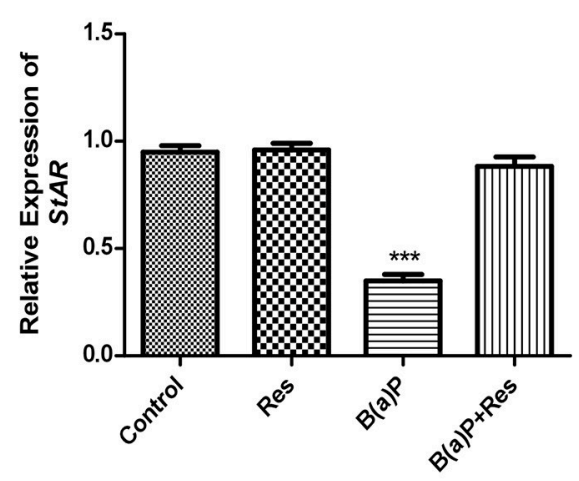

Result
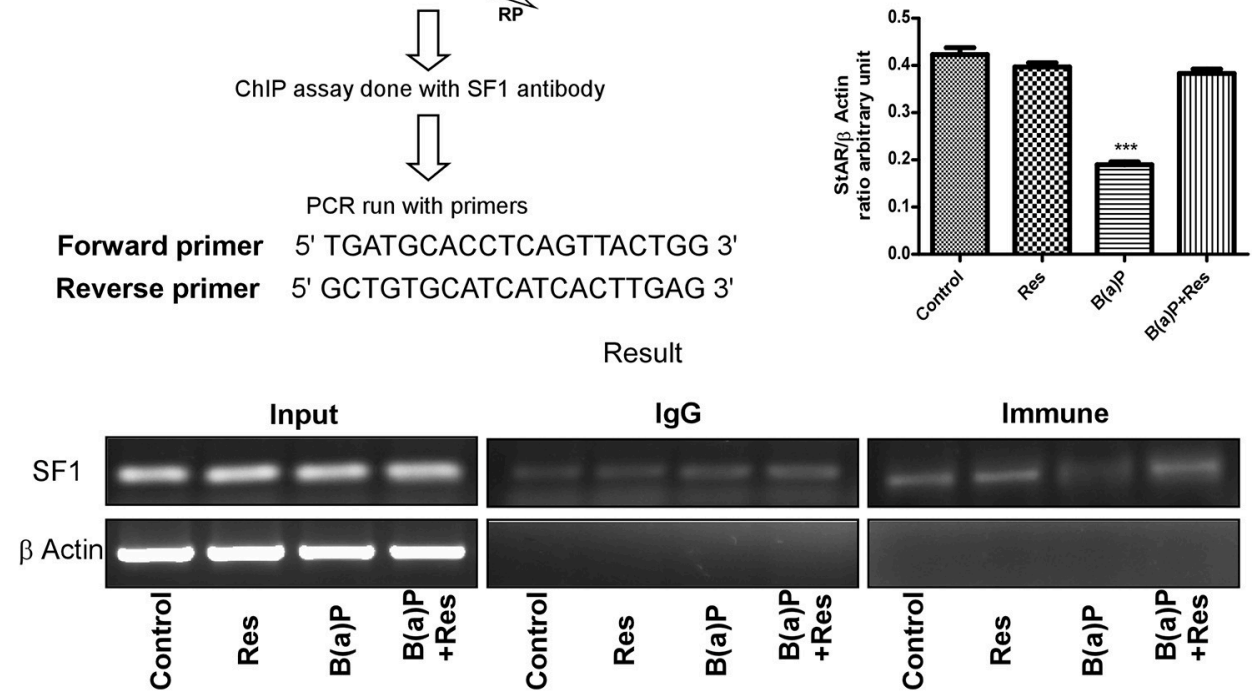

FIGURE 7 | Quantitative real time PCR analysis of (A) SF1 and (B) StAR expression. (C) Schematic representation of the StAR promoter and the sequence of the forward and reverse primer used for ChIP analysis. ChIP assay in isolated Leydig cells treated with B(a)P and Res determining the recruitment of SF1 to the StAR promoter. The corresponding histogram exhibit the densitometric quantification of ChIP result, expressing mean \pm SEM of relative arbitrary units. One-way ANOVA was followed by Dunnett multiple comparison test. The level of significance was set at ${ }^{\star \star \star}(P<0.001)$; ${ }^{\star \star}(P \leq 0.01-0.001)$ as compared with control. $\mathrm{B}(\mathrm{a}) \mathrm{P}$, Benzo(a)pyrene; Res, Resveratrol.

Leydig cells are very much sensitive to oxidative stress and they possess strong anti-oxidant mechanism to fight with the oxidative stress (29). Our findings documented that $\mathrm{B}(\mathrm{a}) \mathrm{P}$ exposure induced ROS generation in Leydig cells as well as transcriptional regulation of antioxidant defensive enzymes were deregulated. There is a strong correlation between the oxidative stress and testicular steroidogenesis (29). Herein $\mathrm{B}(\mathrm{a}) \mathrm{P}$ induced decease in circulating and intra-testicular testosterone level strengthened the concept. Along with that the translational and transcriptional level of steroidogenesis regulatory molecules (CYP11A1, $3 \beta$ HSD, $17 \beta$ HSD), and StAR were significantly altered in Leydig cells. $\mathrm{B}(\mathrm{a}) \mathrm{P}$ induced steroidogenic dysfunction particularly altering anti-oxidative defense system in testicular Leydig cells. Our findings are in accordance with previous observations that
ROS mediated excessive oxidative stress inhibits steroidogenesis $(24,29)$.

p38 MAPK is the stress induced kinase which is activated by oxidative stress and has been shown to be activated by ROS in testis and its activation induce damage in antioxidant mechanism of cell that in turn increase ROS generation (30-32). Activation of the p38 MAPK signaling pathway is functionally linked to the oxidative stress response and mediates its inhibitory effect on steroidogenesis $(24,33)$. Our findings indicated that $\mathrm{B}(\mathrm{a}) \mathrm{P}$ exposure induces oxidative stress and p38 MAPK activation in Leydig cells. And this p38 MAPK activation is triggered by the oxidative stress and decrease in the transcriptional regulation of anti-oxidant enzymes (SOD1, SOD2, Catalase and GPx1). The findings also revealed that $\mathrm{B}(\mathrm{a}) \mathrm{P}$ exposure induced activation of $\mathrm{p} 38 \mathrm{MAPK}$ and inhibited 


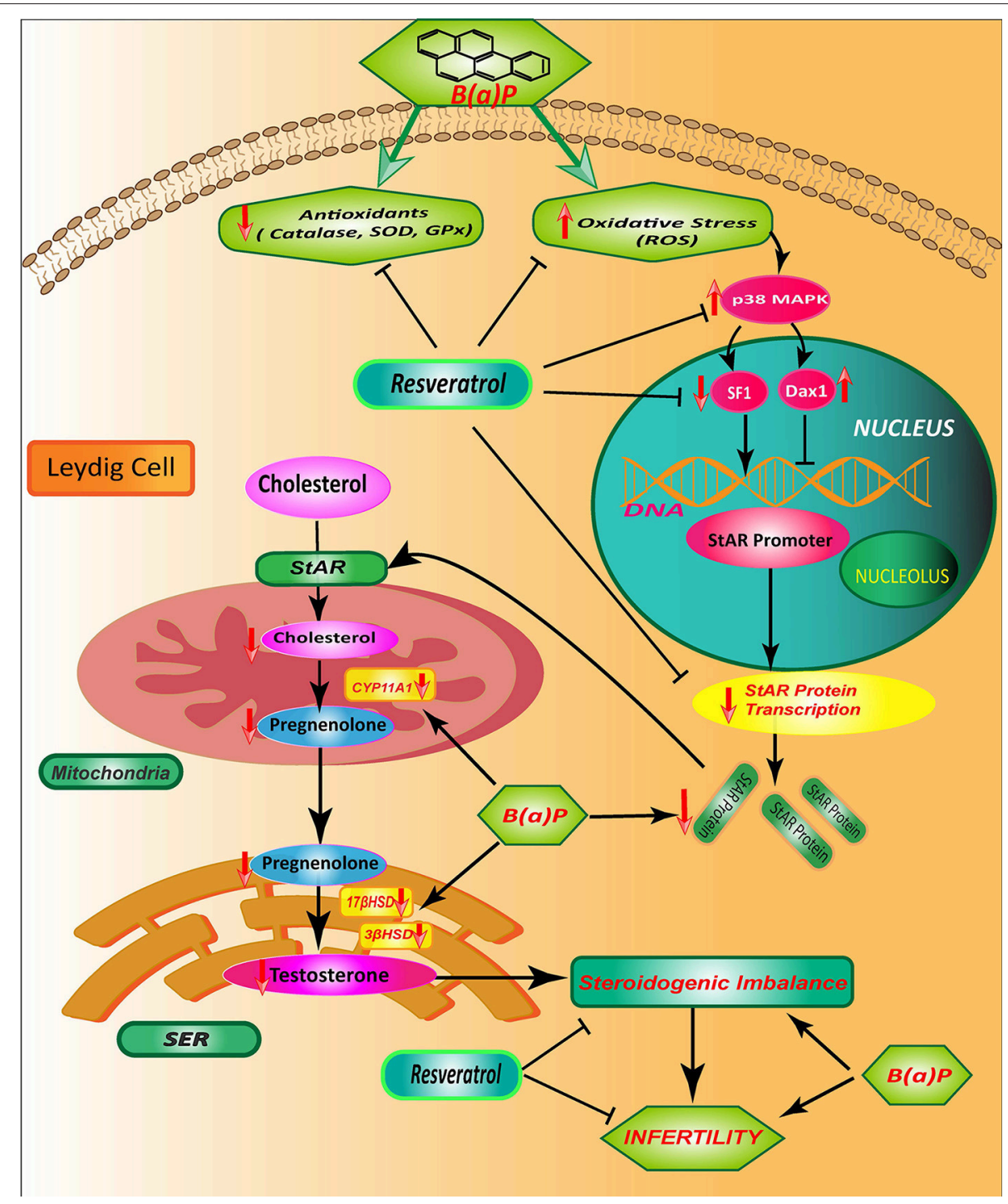

FIGURE 8 | Schematic diagram showing the mode of protective action of Res on $B(a) P$ induced Leydig cell steroidogenic dysfunction. $B(a) P$ generates oxidative stress, activates p38 MAPK and decreases StAR protein production; that cumulatively impairs the testicular steroidogenesis. Res prevent oxidative stress and associated p38 MAPK activation. Res administration also improves StAR expression and SF1 binding to StAR promoter. Thus, Res protects against B(a)P induced down-Regulation of Leydig cell steroidogenesis that involves MAPK activation and modulation of SF1. B(a)P, Benzo(a)pyrene; Res, Resveratrol.

steroidogenesis in Leydig cells. StAR being the major target for $\mathrm{B}(\mathrm{a}) \mathrm{P}$ induced steroidogenic dysfunction $(4,6)$, we tried to find out the link between StAR and p38MAPK activation under the influence of $\mathrm{B}(\mathrm{a}) \mathrm{P}$ induced oxidative stress. In vitro studies showed that blocking the activity of p38 MAPK significantly restored StAR expression, in the presence of $\mathrm{B}(\mathrm{a}) \mathrm{P}$. This established that $\mathrm{B}(\mathrm{a}) \mathrm{P}$ induced StAR mediated steroidogenic dysfunction is linked with the activation of p38 MAPK.

Our selection for Resveratrol (Res) was based upon its natural ability to act as an anti-oxidant and AhR antagonist has been supported by ours as well as others in previous studies $(6,22,34)$. Herein our results established that Res being an anti-oxidant effectively prevented oxidative stress in Leydig cells. Beside that
Res prevented $\mathrm{B}(\mathrm{a}) \mathrm{P}$ induced $\mathrm{p} 38$ MAPK activation and restored StAR expression and/or steroidogenesis.

StAR protein plays the pivotal role in the acute phase of steroidogenesis, mediating the rate-limiting translocation of cholesterol from the outer to the inner mitochondrial membrane, where side-chain cleavage enzyme (P450scc; Cyp11A) carries out the first committed step in steroidogenesis (35), i.e., conversion of cholesterol to pregnenolone. StAR is the major target of most of the endocrine disrupting compounds $(10,36)$. The transcriptional regulation of StAR gene is complex with numerous factors involved in StAR transcription. Among several transcription factors that regulate StAR expression, SF1 and DAX1 are the most common players (14). SF1 is an important factor for the proper functioning of StAR promoter. Analysis of 
the StAR promoter region in the rat, mouse, and human has revealed the presence of multiple SF-1 binding sites (18). B(a)P treatment prevented the recruitment of SF1 to the StAR proximal promoter region. Whereas, Res treatment was increased the SF1 recruitment to the promoter. At the same time western blot and immune-cytochemical findings exhibited that $\mathrm{B}(\mathrm{a}) \mathrm{P}$ downregulate the SF1 expression and Res co-treatment significantly improved SF1 expression. Whereas, DAX1 also represses the promoter activity of several steroidogenic genes including StAR, Cyp11A, Cyp19 etc. (35). In StAR promoter DAX1 exerts its function via its antagonistic activity with SF1.

Experimental outcomes thus suggested that $\mathrm{B}(\mathrm{a}) \mathrm{P}$ exposure induced oxidative stress and steroidogenic dysfunction in Leydig cells. Res effectively prevented ROS generation and p38 MAPK activation and thus protected steroidogenesis in Leydig cells and conserved male reproductive health.

Altogether, the data indicate that $\mathrm{B}(\mathrm{a}) \mathrm{P}$ interrupted Leydig cell steroidogenesis via down-regulating StAR expression. B(a)P exposure resulted oxidative stress mediated activation of stress kinase p38 MAPK. Experimental findings showed the inhibitory effect of p38 MAPK on Leydig cell steroidogenesis in in-vivo and in-vitro through the decrease in StAR gene expression. Furthermore, B(a)P induced decrease in SF1 expression could also play an important role in this molecular interplay. Res being a potent anti-oxidant ameliorated the $\mathrm{B}(\mathrm{a}) \mathrm{P}$ induced $\mathrm{p} 38$ MAPK mediated inhibition of StAR gene transcription and diminution of steroidogenesis.

Our findings suggested that $\mathrm{B}(\mathrm{a}) \mathrm{P}$ treatment activated oxidative stress induced p38MAPK in both primary and TM3 Leydig cells. And subsequently impaired steroidogenesis by the modulation of StAR expression (Figure 8). SF1 is another major player which is associated with the regulation of the promoter activity of StAR. In recent times many natural dietary phytochemicals have been selected for clinical studies. These

\section{REFERENCES}

1. Wong EWP, Cheng CY. Impacts of environmental toxicants on male reproductive dysfunction. Trends Pharmacol Sci. (2011) 32:290-9. doi: 10.1016/j.tips.2011.01.001

2. Jeng HA. Exposure to endocrine disrupting chemicals and male reproductive health. Front Public Health. (2014) 2:55. doi: 10.3389/fpubh.2014.00055

3. Oh S. Disturbance in testosterone production in leydig cells by polycyclic aromatic hydevrepocarbons. Dev Reproduc. (2014) 18:187-95. doi: 10.12717/devrep.2014.18. 4.187

4. Chung JY, Kim YJ, Kim JY, Lee SG, Park JE, Kim WR, et al. Benzo[a]pyrene reduces testosterone production in rat Leydig cells via a direct disturbance of testicular steroidogenic machinery. Environ Health Perspect. (2011) 119:156974. doi: 10.1289/ehp.1003391

5. Banerjee B, Chakraborty S, Ghosh D, Raha S, Sen PC, Jana K. Benzo(a)pyrene induced p53 mediated male germ cell apoptosis: synergistic protective effects of curcumin and resveratrol. Front Pharmacol. (2016) 7:245. doi: 10.3389/fphar.2016.00245

6. Banerjee B, Nandi P, Chakraborty S, Raha S, Sen PC, Jana K. Resveratrol ameliorates benzo(a)pyrene induced testicular dysfunction and apoptosis: involvement of p38 MAPK/ATF2/iNOS signalling. J Nutr Biochem. (2016) 34:17-29. doi: 10.1016/j.jnutbio.20 16.04 .00 compounds typically involve multiple signaling transduction pathways. They themselves or their synthetic analogs have several aspects of research. From our findings it can be concluded that Resveratrol may turn up with new hope in the field of environmental toxicity induced reproductive dysfunctions. However, there are several developmental challenges need to be overcome to establish it as a functional molecule. Moreover, there is not enough evidence to recommend the consumption of resveratrol to combat against $\mathrm{B}(\mathrm{a}) \mathrm{P}$ induced toxicity in human. Further human clinical trials are needed to establish the exact dosage requirements of resveratrol against environmental reproductive toxicants.

\section{ETHICS STATEMENT}

Institutional Animal Ethics Committee of Bose Institute, Approval No. IAEC/BI/30/2015.

\section{AUTHOR CONTRIBUTIONS}

$\mathrm{BB}, \mathrm{SC}, \mathrm{PC}$, and $\mathrm{KJ}$ conceived, designed, and performed the experiments. BB, PC, DG, and KJ wrote the manuscript.

\section{FUNDING}

This work has been financially supported by DST Fast Track Young Scientist Scheme (DST No: SR/FT/LS-053/2009 dated June 12, 2012), Govt. of India.

\section{ACKNOWLEDGMENTS}

We would like to acknowledge R. Dutta, A. Poddar, A. Basu, and K. Das for their technical support. Authors acknowledge Bose Institute for providing the instrumental facilities.
7. Hales DB, Allen JA, Shankara T, Janus P, Buck S, Diemer T, et al Mitochondrial function in leydig cell steroidogenesis. Ann N Y Acad Sci. (2005) 1061:120-34. doi: 10.1196/annals.1336.014

8. Stocco DM, Clark BJ. Role of the steroidogenic acute regulatory protein (StAR) in steroidogenesis. Biochem Pharmacol. (1996) 51:197-205. doi: 10.1016/0006-2952(95)02093-4

9. Miller WL, Bose HS. Early steps in steroidogenesis: intracellular cholesterol trafficking. J Lipid Res. (2011) 52:2111-35. doi: 10.1194/jlr.R016675

10. Walsh LP, Webster DR, Stocco DM. Dimethoate inhibits steroidogenesis by disrupting transcription of the steroidogenic acute regulatory (StAR) gene. $J$ Endocrinol. (2000) 167:253-63.

11. Chung JY, Kim JY, Kim YJ, Jung SJ, Park JE, Lee SG, et al. Cellular defense mechanisms against benzo[a]pyrene in testicular Leydig cells: implications of p53, aryl-hydrocarbon receptor, and cytochrome P450 1A1 status. Endocrinology. (2007) 148:6134-44. doi: 10.1210/en.2007-0006

12. Sugawara T, Kiriakidou M, McAllister JM, Holt JA, Arakane F, Strauss, JF, $3^{\text {rd }}$ Regulation of expression of the steroidogenic acute regulatory protein (StAR) gene: a central role for steroidogenic factor 1. Steroids. (1997) 62:5-9.

13. Rust W, Stedronsky K, Tillmann G, Morley S, Walther N, Ivell R. The role of SF-1/Ad4BP in the control of the bovine gene for the steroidogenic acute regulatory (StAR) protein. J Mol Endocrinol. (1998) 21:189-200.

14. Reinhart AJ, Williams SC, Stocco DM. Transcriptional regulation of the StAR gene. Mol Cell Endocrinol. (1999) 151:161-169. doi: 10.1016/S0303-7207(98)00257-3 
15. Lee J, Yang DJ, Lee S, Hammer GD, Kim KW, Elmquist JK. Nutritional conditions regulate transcriptional activity of SF-1 by controlling sumoylation and ubiquitination. Sci Rep. (2016) 6:19143. doi: 10.1038/srep19143

16. Sandhoff TW, McLean MP. Repression of the rat steroidogenic acute regulatory (StAR) protein gene by PGF2alpha is modulated by the negative transcription factor DAX-1. Endocrine. (1999) 10:83-91. doi: 10.1385/endo:10:1:83

17. Manna PR, Eubank DW, Stocco DM. Assessment of the role of activator protein-1 on transcription of the mouse steroidogenic acute regulatory protein gene. Mol Endocrinol. (2004) 18:558-73. doi: 10.1210/me.2003-0223

18. Sandhoff TW, Hales DB, Hales KH, McLean MP. Transcriptional regulation of the rat steroidogenic acute regulatory protein gene by steroidogenic factor 1. Endocrinology. (1998) 139:4820-31.

19. Aesoy R, Mellgren G, Morohashi K, Lund J. Activation of cAMPdependent protein kinase increases the protein level of steroidogenic factor-1. Endocrinology. (2002) 143:295-303. doi: 10.1210/endo.143.1.8599

20. Tajima K, Dantes A, Yao Z, Sorokina K, Kotsuji F, Seger R, et al. Down-regulation of steroidogenic response to gonadotropins in human and rat preovulatory granulosa cells involves mitogen-activated protein kinase activation and modulation of DAX-1 and steroidogenic factor1. J Clin Endocrinol Metab. (2003) 88:2288-99. doi: 10.1210/jc.2002020913

21. Zaidi SK, Shen W-J, Bittner S, Bittner A, McLean MP, Han J, et al. p38 MAPK regulates steroidogenesis through transcriptional repression of StAR gene. $J$ Mol Endocrinol. (2014) 53:1-16. doi: 10.1530/JME-13-0287

22. Berge G, Øvrebø S, Botnen IV, Hewer A, Phillips DH, Haugen A, et al. Resveratrol inhibits benzo[a]pyrene-DNA adduct formation in human bronchial epithelial cells. Br J Cancer. (2004) 91:333-8. doi: $10.1038 /$ sj.bjc. 6601898

23. Kuo WY, Tang TK. Effects of G6PD overexpression in NIH3T3 cells treated with tert-butyl hydroperoxide or paraquat. Free Radic Biol Med. (1998) 24:1130-8.

24. Abidi P, Zhang H, Zaidi SM, Shen WJ, Leers-Sucheta S, Cortez Y, et al. Oxidative stress-induced inhibition of adrenal steroidogenesis requires participation of p38 mitogen-activated protein kinase signaling pathway. $J$ Endocrinol. (2008) 198:193-207. doi: 10.1677/joe-07-0570

25. Val $P$, Lefrançois-Martinez A-M, Veyssière G, Martinez A. SF-1 a key player in the development and differentiation of steroidogenic tissues. Nuclear Receptor. (2003) 1:8. doi: 10.1186/14781336-1-8

26. Stocco BJC, Stocco DM. The steroidogenic acute regulatory protein (StAR). In: Clark BJ, Stocco DM, editors. Cholesterol Transporters of the START Domain Protein Family in Health and Disease. New York, NY: Springer Science (2014). p. 15-47.
27. Saez JM. Leydig cells: endocrine, paracrine, and autocrine regulation. Endocr Rev. (1994) 15:574-626. doi: 10.1210/edrv-15-5-574

28. Boström C-E, Gerde P, Hanberg A, Jernström B, Johansson C, Kyrklund $\mathrm{T}$, et al. Cancer risk assessment, indicators, and guidelines for polycyclic aromatic hydrocarbons in the ambient air. Environ Health Perspect. (2002) 110:451-88. doi: 10.1289/ehp.110-1241197

29. Turner TT, Lysiak JJ. Oxidative stress: a common factor in testicular dysfunction. J Androl. (2008) 29:488-98. doi: 10.2164/jandrol.108.005132

30. Herlaar E, Brown Z. p38 MAPK signalling cascades in inflammatory disease. Mol Med Today. (1999) 5:439-47.

31. Torres M. Mitogen-activated protein kinase pathways in redox signaling Front Biosci. (2003) 8:d369-391.

32. Vera Y, Erkkila K, Wang C, Nunez C, Kyttanen S, Lue Y, et al. Involvement of p38 mitogen-activated protein kinase and inducible nitric oxide synthase in apoptotic signaling of murine and human male germ cells after hormone deprivation. Mol Endocrinol. (2006) 20:1597-609. doi: 10.1210/me.2005-0395

33. Powazniak Y, Kempfer AC, de la Paz Dominguez M, Farias C, Keller L, Calderazzo JC, et al. Effect of estradiol, progesterone and testosterone on apoptosis- and proliferation-induced MAPK signaling in human umbilical vein endothelial cells. Mol Med Rep. (2009) 2:441-7. doi: 10.3892/mmr_00000119

34. Revel A, Raanani H, Younglai E, Xu J, Han R, Savouret JF, et al. Resveratrol, a natural aryl hydrocarbon receptor antagonist, protects sperm from DNA damage and apoptosis caused by benzo(a)pyrene. Reprod Toxicol. (2001) 15:479-86

35. Hu J, Zhang Z, Shen W-J, Azhar S. Cellular cholesterol delivery, intracellular processing and utilization for biosynthesis of steroid hormones. Nutr Metabol. (2010) 7:47. doi: 10.1186/1743-7075-7-47

36. Walsh LP, McCormick C, Martin C, Stocco DM. Roundup inhibits steroidogenesis by disrupting steroidogenic acute regulatory (StAR) protein expression. Environ Health Perspect. (2000) 108:769-76. doi: $10.1289 /$ ehp. 00108769

Conflict of Interest Statement: The authors declare that the research was conducted in the absence of any commercial or financial relationships that could be construed as a potential conflict of interest.

Copyright (c) 2019 Banerjee, Chakraborty, Chakraborty, Ghosh and Jana. This is an open-access article distributed under the terms of the Creative Commons Attribution License (CC BY). The use, distribution or reproduction in other forums is permitted, provided the original author(s) and the copyright owner(s) are credited and that the original publication in this journal is cited, in accordance with accepted academic practice. No use, distribution or reproduction is permitted which does not comply with these terms. 